\title{
SEMANTIC BIM AND GIS MODELLING FOR ENERGY-EFFICIENT BUILDINGS INTEGRATED IN A HEALTHCARE DISTRICT
}

\author{
R. Sebastian ${ }^{\text {a, } * \text {, H.M. Böhms }}{ }^{\text {a }}$ P. Bonsma ${ }^{\text {a }}$, P.W. van den Helm ${ }^{\text {a }}$
}

${ }^{a}$ TNO Technical Sciences, Expertise Centre of Building and Civil Engineering, Van Mourik Broekmanweg 6, 2826XE Delft, The Netherlands - (rizal.sebastian, michel.bohms, peter.bonsma, pim.vandenhelm)@tno.nl

KEY WORDS: Building Information Modelling (BIM), Geospatial Information System (GIS), Energy-efficient buildings (EeB), open inter-operability, semantics-driven design

\begin{abstract}
:
The subject of energy-efficient buildings $(\mathrm{EeB})$ is among the most urgent research priorities in the European Union (EU). In order to achieve the broadest impact, innovative approaches to EeB need to resolve challenges at the neighbourhood level, instead of only focusing on improvements of individual buildings. For this purpose, the design phase of new building projects as well as building retrofitting projects is the crucial moment for integrating multi-scale EeB solutions.

In EeB design process, clients, architects, technical designers, contractors, and end-users altogether need new methods and tools for designing energy-efficiency buildings integrated in their neighbourhoods. Since the scope of designing covers multiple dimensions, the new design methodology relies on the inter-operability between Building Information Modelling (BIM) and Geospatial Information Systems (GIS). Design for EeB optimisation needs to put attention on the inter-connections between the architectural systems and the MEP/HVAC systems, as well as on the relation of Product Lifecycle Modelling (PLM), Building Management Systems (BMS), BIM and GIS.

This paper is descriptive and it presents an actual EU FP7 large-scale collaborative research project titled STREAMER. The research on the inter-operability between BIM and GIS for holistic design of energy-efficient buildings in neighbourhood scale is supported by real case studies of mixed-use healthcare districts. The new design methodology encompasses all scales and all lifecycle phases of the built environment, as well as the whole lifecycle of the information models that comprises: Building Information Model (BIM), Building Assembly Model (BAM), Building Energy Model (BEM), and Building Operation Optimisation Model (BOOM).
\end{abstract}

\section{INTRODUCTION}

The subject of energy-efficient buildings $(\mathrm{EeB})$ is among the most urgent research priorities in the European Union (EU). In order to achieve the broadest impact, EeB approach needs to resolve challenges at the neighbourhood level, instead of only focusing on improvements of individual buildings (Koch et al., 2012). State-of-the-art EeB technologies are available, but they can only function optimally if well-integrated in the design of the building and district energy systems, taking into account the whole lifecycle's impacts. Therefore, the design phase of new building projects as well as building retrofitting projects is the crucial moment for integrating multi-scale EeB solutions.

In order to achieve the EeB goal, serious attention should be given to hospital and other buildings integrated in a healthcare district. Healthcare buildings play a key factor for a sustainable community, but their energy use and carbon emission are among the highest of all building types. A hospital -which is a part of a healthcare district- uses 2.5 times more energy than an office in average. There are some 15,000 hospitals in the EU responsible for at least $5 \%$ of the annual EU's carbon emission ( 250 million tonnes). Healthcare accounts for nearly $10 \%$ of EU's GDP, and hospitals can take up to $60 \%$ of a country's health expenditure (BPIE, 2011; EuHPN, 2010; HOPE, 2012).
The critical bottleneck to achieve energy-efficient healthcare districts is the inadequacy of the existing design methodologies to create holistic EeB solutions at the neighbourhood level. The 'top 3' challenges are as follows (Bonnema et al., 2010; EPTA, 2007; Schneider Electric, 2010). First, there is a lack of a holistic approach to tackle multi-dimensional complexity. The design of an energy-efficient neighbourhood is not only about technology, but also about user activities, neighbourhood infrastructure, and building operations. The existing design methodologies are incapable of integrating knowledge from architectural, MEP, HVAC and medical domains. Neither can they retrieve the tacit knowledge from the experts, building operators and occupants. Second, there is a lack of a multidimensional optimisation (i.e. between components, buildings and neighbourhood). The greatest potentials of $\mathrm{EeB}$ optimisation through holistic and systemic designs are unexploited. The improvements are still fragmented and limited to individual systems. Trial-and-error approach causes many ad hoc changes during the construction stage. This hampers the optimal configuration of the solutions for whole lifecycle benefits as the design solutions cannot cope with rapidly changing healthcare policies, processes and technologies. Third, very often the design process begins with an ad hoc and timeconsuming exploration of the problems and the possible solutions. A lot of changes occur during the planning/design stage that takes many years before realisation. The building

\footnotetext{
* Corresponding author.
} 
operation experience is not well apprehended due to inadequate post-occupancy evaluation. Most design teams are dismissed soon after the design or project delivery. The lessons-learned from previous design projects are ill-documented and not reused by new design teams, causing a lack of precedence-based approach to designing new energy-efficient buildings (Nauta et al., 2009).

In order to tackle the abovementioned bottleneck, clients, architects, technical designers, contractors, and end-users really need a breakthrough in design methodology for energy-efficient healthcare buildings integrated in their neighbourhoods. The new design methodology needs to be geared to achieve real EeB optimisation in 3 key areas (Singer et al., 2009; Johnson Control, 2010; Nedin, 2011). First, the functional and technical optimisation of the spatial layout and the building envelope directly related to innovative services and building operations within the neighbourhood and surrounding areas. Second, the cost-effective optimisation of the MEP and HVAC systems in the buildings, taking into account the inter-dependencies between building components and energy systems. New design methodology needs to solve the most crucial design failures that cause transmission loss / efficiency loss between equipment and buildings during operation, especially when modern equipment is installed in existing building or energy systems. Third, optimal interaction between the building's and neighbourhood's energy systems in the district (e.g. smart grid, smart use of district heating/cooling and energy generation).

Since the scope of designing covers multiple dimensions and scale levels, the new design methodology relies on the interoperability between Building Information Modelling (BIM) and Geospatial Information Systems (GIS) (Przybyla, 2010; Sebastian et al, 2013). For instance, EeB optimisation can only be done through the inter-connections between the architectural systems and the MEP/HVAC systems, through Product Lifecycle Modelling (PLM) and Building Management Systems (BMS) in relation with BIM and GIS). The new design methodology needs to encompass all scales and all lifecycle phases of the built environment, as well as to comprise the whole lifecycle of the information models: Building Information Model (BIM), Building Assembly Model (BAM), Building Energy Model (BEM), and Building Operation Optimisation Model (BOOM) (McLeamy, 2010).

This paper presents an actual EU FP7 collaborative research project titled STREAMER, which involves a large consortium consists of industrial partners and research institutes. The research is supported by real case studies of mixed-use healthcare districts in four different EU countries. A healthcare district is an example of a neighbourhood or a campus area with an integrated energy system, which consists of various buildings (i.e. hospitals and clinics; research and educational buildings; temporary care homes; rehabilitation and sport facilities; offices, retails, and logistic buildings; power and control facilities). In almost every European city, there is at least one healthcare district which consumes significant amount of the energy supply for the city; therefore, its impact on the city's energy performance is enormous (HOPE, 2012).

This paper is descriptive and presents the multi-disciplinary approach that underpins the collaborative research project. It reviews the state-of-the-art of BIM and GIS for collaborative design, and pin-points the areas where innovations are urgently needed. It explains the composition of the research consortium and role distribution between the partners, as well as the multi- level research methodology, including the description of the demonstration cases. Finally, it provides an insight into the expected development within the collaborative research projects in the coming years.

\section{STATE-OF-THE-ART AND TARGETED PROGRESS OF BIM AND GIS FOR COLLABORATIVE DESIGN}

In relation with the use of BIM and GIS, the STREAMER research aims to progress from the state-of-the-art by developing and deploying a semantics-design approach. Semantics-driven design within this context is defined as: 'the methodology of collaborative design, which relies on intelligent performance analysis of design models that embed the perceptions and interpretations of design teams, stakeholders, and building occupants'. It is a methodology of knowledgebased designing that includes not only the product/object/technology knowledge, but also the intellectual asset of tacit human knowledge and empirical data of building operation (Pauwels, 2012; Storti, 2010; Nauta et al., 2009).

In Semantic BIM, the 'translation and interpretation' processes between the experts/users from various knowledge domains and intelligent systems are embedded. Everyone is working with the coherent and interoperable data and definitions, so communication errors can be prevented (Pauwels, 2012). BIM moves the whole industry forward from its current task automation of project and paper processes (3D CAD, animation, linked databases, spreadsheets, and 2D CAD drawings) towards an integrated and interoperable workflow where these tasks are embedded in a coordinated and collaborative process that maximizes computing capabilities based upon an integrated and shared information model (Eastman et al., 2008). Beyond this, STREAMER introduces Semantic BIM + GIS, which is a new generation of Semantic Building and Geo Information Modelling that includes the process intelligence along with the user's perceptions and experience, comprising the knowledge of building operations; functional and technical problems; optimisation potentials. In this methodology, inter-connected product, process and knowledge modelling for energy-efficient buildings and neighbourhoods is fully supported by interoperable BIM and GIS in a Semantic Web environment.

STREAMER aims to enable an open information capture, exchange, sharing, comparison and storage of the relevant building and GIS models for designing energy-efficient buildings in healthcare districts. As illustrated in Figure 1, in a healthcare district where no building can be regarded independent to the others, the connectivity between BIM and GIS is an urgent need. The progress through STREAMER beyond the state-of-the-art regarding BIM - GIS interoperability and parametric modelling can be briefly described as follows.

Until now, the interoperability of data models is limited within the same domain. Each information model is usually designed for a particular domain, e.g. AEC (Architecture, Engineering, Construction) or urban planning. Besides, connecting different Levels of Detail (LoD) is still difficult; and moreover, none of the existing standardized data models covers a holistic approach for building complexes throughout the lifecycle (Sebastian et al., 2013). An open standard for describing relations between different semantic data models (e.g. between IFC and CityGML) especially in distributed environment has not yet existed (El-Mekawy et al., 2010; Berlo et al., 2011; Ji et al., 
2011). A generic parametric rule or slightly different profile (then predefined) is not supported until now. For urban environments at all level of detail no standards for parametrical modelling have been defined.

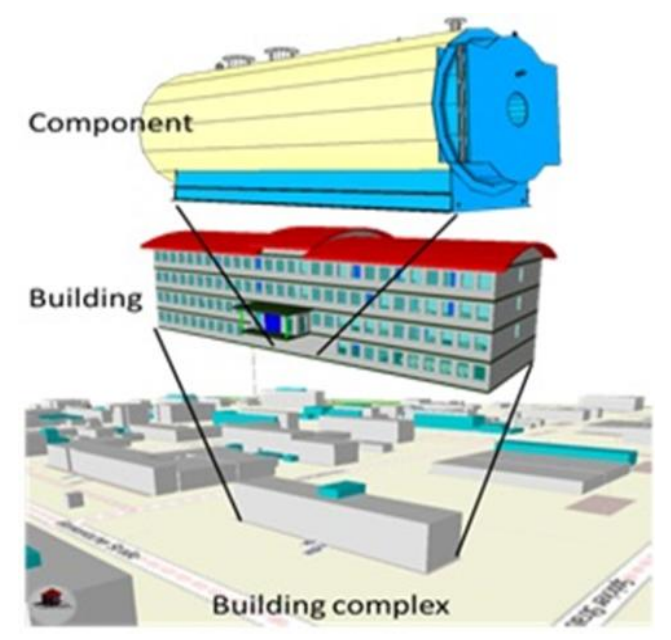

Figure 1. Level of details between component - building area/building complex (source: STREAMER research proposal)

BuildingSMART provides BIM through IFC (Industry Foundation Classes) with an open data model for storing information of a rich set of aspects during many of the stages of the lifecycle of a building (BuildingSMART, 2011). Utility network, transportation networks, land use and vegetation are not yet in the scope of the current IFC. There are only few data models which are able to represent a real world object parametrically. One example for such a model is VDI 3805 for building services components. In this model all available variants of a specific product can be described parametrically. By specifying technical and geometrical requirements a specific product can be configured.

The utility network, transportation network, land use and vegetation beyond buildings - which are not yet in the scope of the current IFC - can be handled by the open standard CityGML developed by Open Geospatial Consortium (OGC, 2011). CityGML also contains buildings, but the LoD is less compared to the details in an IFC model. The rich set of aspects in IFC is still missing in CityGML. So none of the existing standardized data models can cover a holistic approach for building complexes throughout the lifecycle. It is hardly possible to cover and manage all aspects of the lifecycle, either of a single building or of a larger building ensemble in one model. The interoperability between models and/or the relations between models are lacking. In case of retrofitting projects of large healthcare districts, the combination between the existing and new buildings need to be handled by a combination of BIM and GIS technologies.

STREAMER will tackle the challenge of a cross-domain modelling approach using the optimal model for each process in the lifecycle that takes into account the cross-domain relationships. This approach will enable all project participants to optimise building complexes on a building level as well as on the building complex level or even on a wider neighbourhood level. The relation between different models, e.g. detailed building model (in BIM) and its neighbourhood (in GIS model), will consider all kind of processes during the lifecycle.
On the component level, fully parametric models will be made available. Until now, for complete buildings no open standard for parametric models is available. In IFC, building parts like doors, windows as well as profiles can have parametric representations as long as these are within most common predefined cases that were foreseen during IFC schema development. In order to find best solutions or to evaluate different planning approaches parametric models are needed, especially in the conceptual design phase (new design and retrofitting) of healthcare districts where the use of ontologies and parametric models are essential. The design alternatives have to be quantified in order to evaluate whether we need a parametric model of the complete building complex, or a library of parametric typology models, in order to sufficiently support the design process regarding optimisation of e.g. energy performance, building operation and lifecycle cost.

Learning from earlier EU research projects, Semantic Web technology has proven to be a good potential for combining semantic data from different sources. Web language standards, among others OWL Web Ontology Language, are able to grab both geometry and semantic information from IFC files through Product Modelling Ontology (PMO). In turn, the flexible and parametric behaviour of OWL helps defining parametric extensions on IFC to make the parametric behaviour more useful.

\section{COLLABORATIVE RESEARCH METHODOLOGY}

The EU FP7 project STREAMER relies on a strategy for a 4year large-scale integrating collaborative project that coherently integrates 2 innovation areas and 4 progressive steps. The 2 main innovation areas are:

- $\quad$ EeB technology innovation, on one side, dealing with the design optimisation based on the building and district typologies as well as the EeB technologies and measures.

- Semantic design innovation, on the other side, dealing with new methodologies and tools to help clients, design teams, building operators and occupants in an effective design collaboration.

The total work in STREAMER will be performed through 4 progressive steps, namely: A) Conceptualisation; B) Configuration; C) Optimisation; D) Generalisation. The collaborative work in STREAMER will proceed in 10 work packages, including: 6 RTD work packages (WPs) as shown in Figure 2.

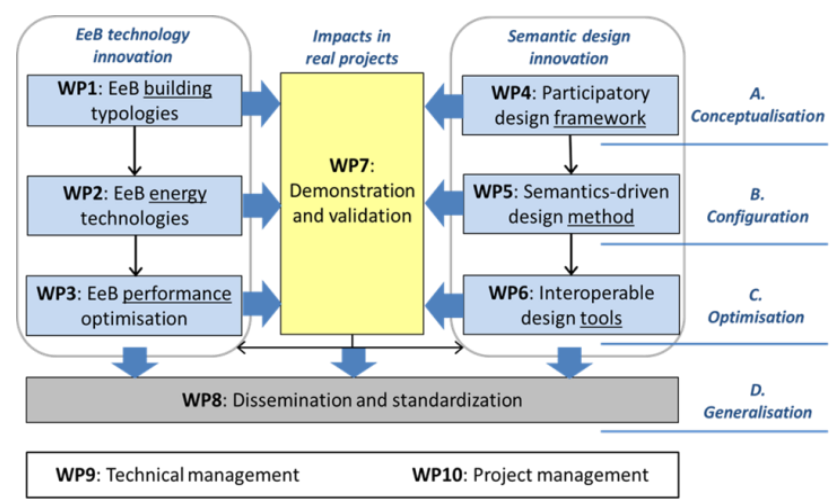

Figure 2. Work packages and their interdependencies 
The STREAMER consortium consists of 20 partners, including design engineering and construction companies; healthcare institutions; research organisations; and public bodies. Together they form the critical mass to assure high research quality and to realise EU-wide impact. The consortium partners represent 5 key professional, R\&D and public policy domains, which are the most essential in developing, optimising, validating and implementing new design methodologies for EeB:

- Professional domain of EeB and environmental design and engineering, with special expertise in sustainable building and urban design.

- Professional domain of building construction, operation, maintenance, and energy management, with special expertise in user-oriented lifecycle design and management.

- $\quad \mathrm{R} \& \mathrm{D}$ domain of building and neighbourhood energy systems, with special expertise in building MEP/HVAC, neighbourhood energy systems, and renewable energy sources.

- R\&D domain of advanced ICT for design practices, with special expertise in BIM, GIS, Semantic Web, Parametric Models, Ontologies, PLM, and the associated open standards IFC and CityGML.

- $\quad$ Public policy and commercial strategy EeB, focusing on sustainable management and transformation of healthcare real estate property.

The supplier's practical knowhow (regarding medical equipment, building components and materials) is covered by technical designers, contractors, and hospitals in the consortium, with comprehensive experience in a very broad range of solutions, products and components. STREAMER openly, objectively and critically covers all available products and components - independent of a single manufacturer.

\section{CASE STUDIES OF ENERGY-EFFICIENT HEALTHCARE DISTRICTS}

The outcomes of the STREAMER project will be validated through action research in the design phase of the new buildings and retrofitting projects in 4 healthcare districts in different EU countries, as described on the next pages. The building, district and project types, sizes and scopes are representative to the EU typologies. All cases are large-scale hospitals in mixed-used healthcare districts including offices and other buildings. Three cases (NL, IT, FR) involve academic hospitals where hospitals are combined with the university facilities.

- NHS, Rotherham, UK

- Rijnstate Ziekenhuis, Arnhem, The Netherlands

- $\quad$ AOUC, Firenze, Italy

- $\quad$ AP-HP, Paris, France

\section{Project description of NHS, Rotherham, UK}

NHS Rotherham is a 500-bed acute unit in the North of England. The district was constructed in phases with the initial building (Phase 1) opening in 1978. Phase 2 was opened in 1984 with Phase 3 opening in 1994. The present size of the main hospital building GIA is around $67,000 \mathrm{~m} 2$ with a Heated Volume of around 179,000 m3.

The whole Building Management System (BMS) is in need of a major upgrade and this would be the prioritised retrofitting project of the district. Allied to the proposed BMS improvements would be major improvement in the overall building fabric. Any improvements in the BMS would be negated if the building itself was inefficient, i.e. poor thermal insulation, single glazed or ill-fitting windows, etc. The Estates Strategy will allow greater utilisation of its existing space and reduce the cost of managing and maintaining buildings.

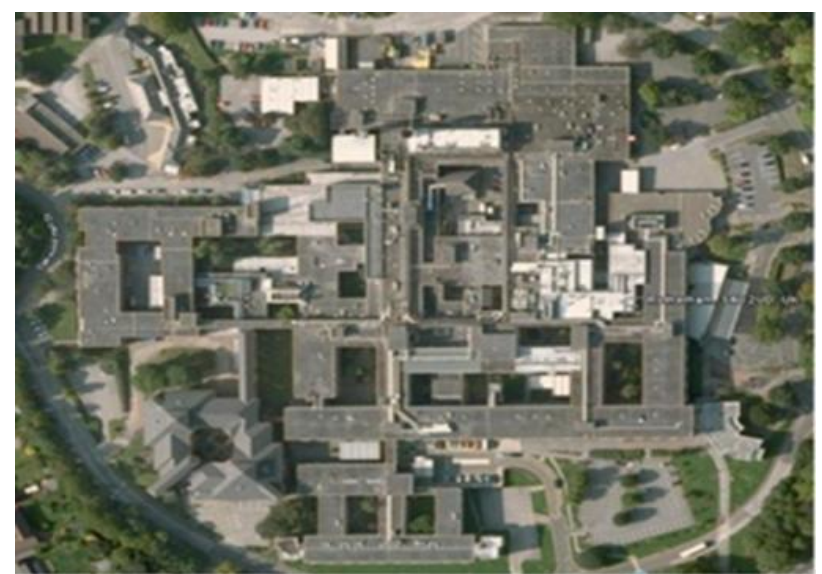

Figure 3. Hospital complex of NHS Rotherham, UK (source: NHS Rotherham)

The Rotherham NHS Foundation Trust (TRFT) participates in the NHS Carbon Management Programme in partnership with the Carbon Trust. A 5 year Carbon Management Plan (CMP) was produced where areas of wastage were identified and addressed. A target of $30 \%$ reduction in building related carbon emissions was set during the life of the CMP.

Project description of Stichting Rijnstate Ziekenhuis, Arnhem, The Netherlands

The Rijnstate healthcare district is situated in the north of Arnhem, the capital town of the Province of Gelderland. It is a $72,000 \mathrm{~m} 2$ large-scale complex which also consists of educational buildings (in conjunction with Radboud University Nijmegen) and is connected to apartment buildings for elderly people.

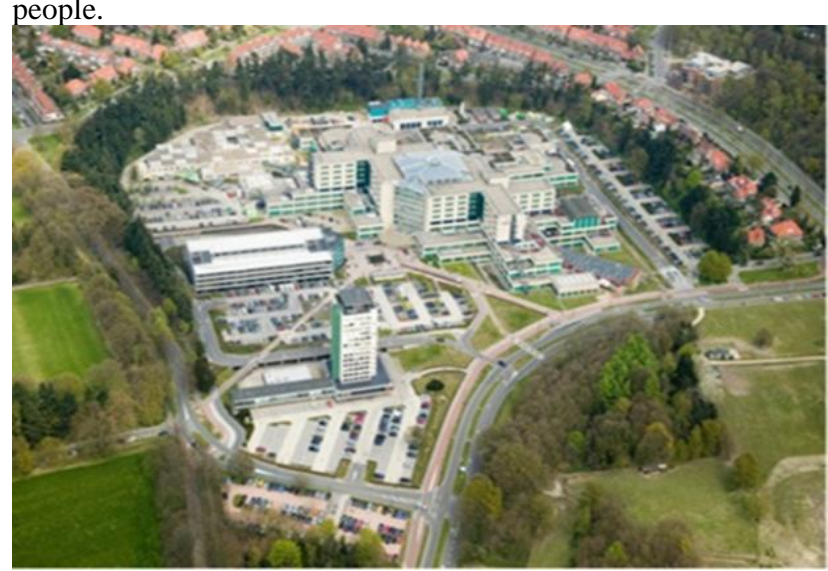

Figure 4. Hospital complex Rijnstate Arnhem, NL (source: Rijnstate)

Currently Rijnstate is preparing a 10,000 m2 large-scale extension project The extension project aims to add several new policlinic buildings, improve the public space for visitors, create a healing environment for patients and high-quality workspaces. The project will be combined with the mid-life 
renovation planned for 2016 to replace the existing, outdated MEP systems with an up-to-date green system with minimum or zero CO2 emission. Based on the new integrated Master Plan which incorporates the goals concerning architecture, landscape, infrastructure, parking and logistics- 5 design scenarios for the extension and large-scale renovation are examined regarding the feasibility in terms of Total Cost of Ownership (TCO) and, at the same time, the contribution to reduction of energy use and $\mathrm{CO} 2$ emission. BIM and GIS will be used at this early-design stage to analyse the 5 scenarios as well as to map the $\mathrm{CO} 2$ footprint of the healthcare district prior to decision-making.

\section{$\underline{\text { Project description of AOUC, Firenze, Italy }}$}

The University Hospital Campus of Careggi (AOC) functions as a district within the urban system of Florence. The healthcare district covers $74,000 \mathrm{~m} 2,170$ health and administrative facilities, 25 Pavilions, 1,650 beds. The hospital, which is part of the university, has 5,670 employees and 130,000 visitors each year. The annual energy use is equivalent to that of 21,000 dwellings. Since 2000, it has reconfigured its buildings to facilitate developments in biotechnology and healthcare.

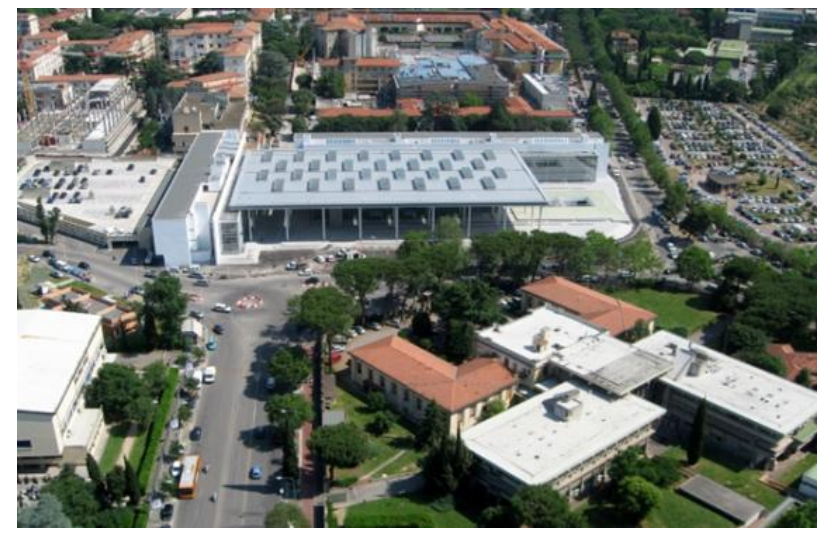

Figure 5: Entrance building in the hospital complex AOUCareggi Firenze, IT (source: Ipostudio/AOUC)

The recently launched strategic plan of sustainable transformations, called "New Careggi" stresses the interdependence and conversion of the pavilion system into an integrated building network. The plan is in full compliance with the complex requirements of a large healthcare institution. The design approach will serve as a precedence of a flexible methodology to absorb and foresee changes and synergies between: building and landscape design; energy, building operation and healthcare management; and district and urban logistics and energy systems. The plan includes a complete overhaul of the entire electricity and heat distribution systems of all buildings within the healthcare and university districts. Energy-efficiency and low-carbon emission are addressed by the new natural gas power tri-generation plant, which produces electricity, heat and chilled water for air conditioning. It meets the today's highest energy saving and environmental standards.

\section{Project description of AP-HP, Paris, France}

Assistance Publique - Hopitaux de Paris (AP-HP) is the University Hospital of "Ile de France" and the largest university hospital in Europe. It employs 90,000 professionals including 20,000 physicians and 70,000 staff members in the public hospital on 37 hospitals grouped into 12 hospital groups (GH). The extensive and diversified real estate spans 3.5 million square meters of built area allocated of 52 hospital sites. AP HP offers a capacity of 23,000 beds including 350 intensive care beds (ICU), and has served more than 7 million patients in 2011.

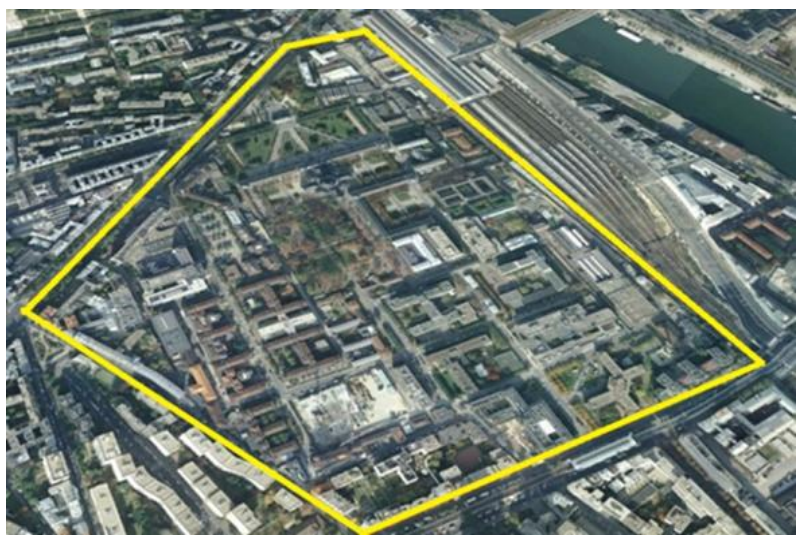

Figure 6. Salpêtrière - C. Foix University Hospital district in Paris (source: GoogleEarth)

Research on design methodology in STREAMER will use the case of buildings integrated in the Salpêtrière - C. Foix University Hospital district in Paris with 1,600 beds in medicine, surgery, acute care and long-term care. They are located on two sites covering a total area of $450,000 \mathrm{~m}^{2}$. The project focuses on the Gaston Cordier building with $26,000 \mathrm{~m}^{2}$ floor area and all emergency and surgery facilities. APHP is in the process of optimizing the design, operation and management of the hospital at the district level within the high-density urban area of Paris. Energy-efficiency goes along with efficient logistic and waste management, the use of alternative energy sources (e.g. biomass) and the realisation of new energy infrastructures (e.g. power plants).

\section{CONCLUDING REMARKS AND DISCUSSIONS ON FURTHER RESEARCH}

This paper presents the 4-year EU FP7 collaborative research project STREAMER, which has very recently started. This paper reviews the research problems and approach, as well as the research consortium and its work plan for the coming period. The implications of this research to current development in BIM and GIS can be summarised as follows.

The key targeted achievements of STREAMER are: 1) generic semantic BIM + GIS typology models as design templates for new and retrofitted energy-efficient buildings integrated in healthcare districts; 2) a framework for BEM (Building Energy Model) which interconnect the design, construction and facility management models throughout the building's lifecycle; and 3) a design decision-support tool which accommodates interactive BIM and GIS design models, analysis of design performance, and stakeholder's requirements, decision criteria and priorities.

Research in STREAMER brings forward an innovative and effective answer to solve the connectivity and interoperability issues between various information models, design and decision-support tools, as well as to solve the actual problems of integrating different Levels of Detail (LoD), especially 
regarding the implementation of open standards of IFC and GML for energy analysis. The most effective solutions rely on the smart inter-connectivity between different types of model and data platforms. Therefore, this research promotes the semantic and geometrical ways for interfacing knowledge, models and tools from the relevant domains. This is much more efficient and user-friendly than adding a "mega-sized integration platform" that is "heavy' and difficult to handle.

The existing technological risks with regards to the open interoperability can be identified as:

- Risk of inefficiency when the research tries to tackle all different types of solutions/standards at the same time. This can be overcome by keeping an up-to-date research priority according to the experts' reviews linked with the BIM, GIS, SW communities.

- Lack of uptake of open-standards and open-source solutions by the software manufacturers. This can be overcome by: a) implementing the open-standards in compliant software; b) aligning with the global trends and demands in connected BIM-GIS and SW; and c) mobilising the critical mass of large construction companies, architectural offices, engineering firms, which can exercise a great influence in software development since they are the main buyers and users of modelling software in the building industry.

Another challenge is related to the issue of data ownership and access, and the commercial and legal sensitivities abound with energy and building data. STREAMER will overcome this by developing an approach to empirical data and analysis in keeping with the best practices in all disciplines, e.g. the medical sciences, which demonstrate that protocols for the handling of sensitive data for research can be both secure and effective for early feedback. STREAMER will establish adequate sets of protocol to unlock data from the range of current sources and the possibilities for involving impartial bodies or institutions (e.g. local authorities or universities) to act as caretakers for the datasets (including those from BIM and BMS).

\section{REFERENCES}

Berlo, L. van, Laat, R., 2011. Integration of BIM and GIS: the Development of CityGML GeoBIM extension. In: Proceedings of 3D Geo-Information Conference, Berlin, Germany.

Bonnema, E., Doebber, I., Pless, S., Torcellini, P., 2010. Development of the advanced energy design guide for small hospitals and healthcare facilities - the $30 \%$ guide, NREL/TP report, Springfield, VA, USA.

BPIE, 2011. A country-by-country review of the energy performance of buildings. BPIE, Brussels, Belgium.

BuildingSMART, 2011. "Industry Foundation Classes Release 2x4 (IFC4)”, http://www.buildingsmarttech.org/ifc/IFC2x4/rc3/html/index.htm (01 Feb 2013).

Eastman, C., Teicholz, P., Sacks, R., Listorn, K., 2008. A BIM Handbook. Wiley and Sons, New Jersey, USA.

El-Mekawy, M., 2010. Integrating BIM and GIS for 3D city modelling: the case of IFC and CityGML. Licentiate Thesis, KTH, Stockholm, Sweden.
EPTA, 2007. Guidelines for energy efficiency in hospitals. EU LIFE ENV project report, Athens, Greece.

EuHPN, 2010. Guidelines and standards for healthcare buildings. European Health Property Network, Durham, UK.

HOPE, 2012. Hospital healthcare Europe 2011/2012. European Hospital and Healthcare Federation, Brussels, Belgium.

Ji Y., Beetz J., Bonsma P., Nisbet N., Katz C. and Borrmann A. (2011). Integration of parametric geometry into IFC-Bridge. In: Proceedings of the 23th forum Bauinformatik, Cork, Ireland.

Johnson Controls, 2010. Energy-efficiency indicator healthcare sector, Institute for Building Efficiency, Washington D.C., USA.

Koch, A., Girard, S., McKoen, K., 2012. Towards a neighbourhood scale for low or zero carbon building projects. Building Research and Information, 40(4).

MacLeamy, P., 2010. "Project effort and impact", http://www.buildingsmartsd.org/ (15 Sep. 2012).

Nauta, J., Michiel, P. (Eds.), 2009. All designers use evidence. GRAS, Groningen, The Netherlands.

Nedin, P., 2011. "The long game: sustainable healthcare design", www.WorldHealthDesign.com (04 Sep. 2012).

OGC, 2011. "CityGML OpenGIS City Geography Markup Language", http://www.opengeospatial.org/standards/citygml (01 Feb 2013).

Pauwels, P., 2012. Reconsidering information system support in architectural design thinking. PhD Dissertation, Universiteit Gent, Gent, Belgium.

Przybyla, J., 2010. The next frontier for BIM: interoperability with GIS. Journal of Building Information Modelling, Fall 2010.

Schneider Electric, 2010. How energy efficiency ensures financial health for hospitals. White paper, North Andover, MA, USA.

Sebastian, R., Bohms, H.M., Helm, P. van den, 2013, BIM and GIS for Low-Disturbance Construction. In: Proceedings of CONVR2013, London, UK.

Singer, B.C., Tschudi, W.F., 2009. High-performance healthcare buildings: a roadmap to improved energy-efficiency. Report, Ernest Orlando Lawrence Berkeley National Laboratory, Berkeley, CA, USA.

Storti, E., 2010. Semantic-driven design and management of knowledge discovery in databases (KDD) processes. $\mathrm{PhD}$ Dissertation, Universita Politecnica delle Merche, Ancona, Italy.

\section{ACKNOWLEDGEMENTS}

The research leading to these results has received funding from the European Community's Seventh Framework Programme under Grant Agreement No. 608739 (Project STREAMER). The first author is the Coordinator of this research project. 